\title{
Retraction
}

\section{Retracted: Some Properties of Fuzzy Quasimetric Spaces}

\author{
International Journal of Mathematics and Mathematical Sciences
}

Received 28 December 2014; Accepted 28 December 2014

Copyright (C) 2015 International Journal of Mathematics and Mathematical Sciences. This is an open access article distributed under the Creative Commons Attribution License, which permits unrestricted use, distribution, and reproduction in any medium, provided the original work is properly cited.

The paper titled "Some Properties of Fuzzy Quasimetric Spaces" [1], published in International Journal of Mathematics and Mathematical Sciences, has been retracted as it is found to contain a substantial amount of material from a number of previously published papers. The most plagiarized papers are as follows: (1) A. George and P. Veeramani, On some results in fuzzy metric spaces, Fuzzy Sets and Systems 64 (1994) 395-399; (2) A. George and P. Veeramani, On some results of analysis for fuzzy metric spaces, Fuzzy Sets and Systems 90 (1997) 365-368; (3) Valentin Gregori and Salvador Romaguera, Some properties of fuzzy metric spaces, Fuzzy Sets and Systems 115 (2000) 485-489; (4) Valentin Gregori and Salvador Romaguera, Fuzzy quasi-metric spaces, Applied General Topology, Volume 5, No. 1, 2004, pp 129-136; (5) J. H. Park, Intuitionistic fuzzy metric spaces, Chaos, Solitons and Fractals 22 (2004), 1039-1046.

\section{References}

[1] A. Mohamad, "Some properties of fuzzy quasimetric spaces," International Journal of Mathematics and Mathematical Sciences, vol. 2010, Article ID 514747, 9 pages, 2010. 